\title{
Mensuração da satisfação dos usuários do sistema municipal de estacionamento rotativo pago
}

\author{
Users satisfaction measurement of the municipal paid rotational parking system
}

Franciane Cougo da Cruz ${ }^{[a]}$, Anderson Cougo da Cruz ${ }^{[b]}$, Paulo Sergio Ceretta ${ }^{[b]}$

\footnotetext{
[a] Instituto Federal de Educação Ciência e Tecnologia Farroupilha (IFFar), Santa Rosa, RS, Brasil

${ }^{[b]}$ Universidade Federal de Santa Maria (UFSM), Santa Maria, RS, Brasil
}

\section{Resumo}

A pesquisa identifica a percepção dos usuários do serviço público de estacionamento rotativo pela aplicação do modelo European Customer Satisfaction Index (ECSI). O estudo mensurou as relações que envolvem usuários do sistema, uma vez que é necessário conquistar a lealdade deles por intermédio da maximização da sua satisfação e, ainda, identificar aspectos considerados como valores importantes para o cliente. Para a quantificação dessa satisfação, utilizou-se o ECSI, modelo estimado pelo método Partial Least Squares-Path Modeling (PLS-PM), que se caracteriza por sua robustez diante de modelos estruturais compostos por dados com falta de normalidade. Foram coletados dados por meio de questionários aplicados, de forma não aleatória, a 401 usuários do sistema na cidade de Bagé, no Estado do Rio Grande do Sul. Os resultados concluem que o usuário considera o serviço satisfatório, e que esse constructo foi mais afetado pela expectativa e imagem do serviço. Os constructos diferem de forma sistemática para renda e idade. À medida que aumentam esses fatores, a tendência é de que exista uma melhor avaliação do sistema de estacionamento rotativo.

Palavras-chave: Mobilidade urbana. Gestão pública. Estacionamento rotativo. Satisfação dos usuários. Partial Least Squares (PLS).

\section{Abstract}

The research identifies the perception of users of the paid public parking service by applying the European Customer Satisfaction Index model (ECSI). The study measured the relationship involving the system users since it is necessary to win their loyalty by maximizing satisfaction and also identifying aspects considered as important values to the client. To quantify this, we used the satisfaction ECSI, PLS-model estimated by the PM method which is characterized by its robustness on structural models composed of data with non-normality. Data were collected through questionnaires, not randomly, applied to 401 system users (Bagé / RS city). The results conclude that the user considers the service satisfactory, and this construct is mostly affected by expectation and service image. The constructs differ systematically by income and age. As these factors increase, the trend is a better assessment of the paid parking system.

Keywords: Urban mobility. Public management. Paid parking. User satisfaction. Partial Least Squares (PLS).

FCC é administradora, mestra, e-mail: franciane.cruz@iffarroupilha.edu.br

ACC é administrador, mestre, e-mail: adm.cougo@gmail.com

PSC é administrador, doutor, e-mail: ceretta10@gmail.com 


\section{Introdução}

A rápida ocupação das cidades, após a Revolução Industrial (século XVIII), infelizmente, não foi acompanhada pela execução de políticas públicas eficazes, o que causou desequilíbrios urbanos e problemas sociais. Diante desse contexto, a Lei no 12.587/2012 (nova Lei da Mobilidade Urbana) estabelece a obrigatoriedade de elaboração do Plano de Mobilidade Urbana (PlanMob), até o ano de 2015, como instrumento de melhoria para municípios com mais de 20 mil habitantes. Esse documento deve integrar-se ao Plano Diretor de cada cidade e prevê, dentre outras medidas, a gestão e a regulamentação de áreas de estacionamento pelo poder público (Brasil, 2012).

A qualificação desse setor nas cidades só se torna possível por meio do desenvolvimento de políticas públicas favoráveis, acompanhadas de gestores públicos que buscam desenvolver maneiras inovadoras de gerenciar seus processos/serviços e gerar novas propostas a fim de solucionar problemas enfrentados pelos cidadãos; assim, a qualidade dos serviços disponibilizados deve estar vinculada à estrutura do processo do serviço (Leite \& Gonçalves, 2007).

No ano de 2011, considerando o desenvolvimento de estudos técnicos de análise de viabilidade, realizou-se a implantação do sistema de estacionamento rotativo pago (SER) na cidade de Bagé, no Estado do Rio Grande do Sul, como forma de garantir a democratização e a rotatividade de veículos nas vagas de estacionamentos centrais. Nesse sentido, com o intento de agregar valor ao serviço e de atender às necessidades geradas pela população, somado aos desafios enfrentados pelo poder público, identifica-se como problemática do estudo verificar qual a percepção dos usuários com relação à satisfação pela utilização do SER, por meio da análise de quatro constructos definidos como antecedentes (qualidade do serviço prestado, valor percebido, imagem, expectativa) e dois como consequentes (lealdade e reclamações). Como objetivo geral, procurou-se avaliar a percepção dos usuários do sistema, estimando as relações de antecedência e consequência envolvidas, considerando os constructos apresentados anteriormente.

A fim de contextualizar o problema proposto, há de se expor que a ação de identificar a satisfação de clientes tornou-se uma preocupação para qualquer instituição, seja ela pública ou privada. A partir da constatação dessa realidade, é possível realizar um direcionamento estratégico de gestão para a melhoria da qualidade do serviço prestado. Identificando a satisfação de usuários do sistema, há a possibilidade de um direcionamento das ações para conquistar e conceder manutenção à lealdade dos clientes, o que é um dos principais objetivos das organizações, visto que é cada vez mais notória a necessidade de se prestar o serviço público com excelência, eficiente e em busca da gestão com foco nos resultados.

Nesse sentido, Congram \& Friedman (1991) afirmam que a qualidade está relacionada à eficiência e à produtividade, e que a sincronia dessa interação faz com que serviços realizados com eficiência evitem a insatisfação dos usuários, custos financeiros e humanos a fim de corrigir falhas causadas pela prestação inadequada de serviços. Já Rossi \& Slongo (1998) destacam que informações sobre os níveis de satisfação das pessoas devem ser uma das maiores prioridades de gestão, assim como a qualidade dos serviços e os resultados alcançados com os clientes. Reconhecer esse princípio de gestão aumenta a importância de priorizar o monitoramento da satisfação dos clientes como forma de avalição do desempenho global do serviço (Marchetti \& Prado, 2004).

Pesquisas como esta são elaboradas para conhecer o comportamento de clientes diante de erros durante a prestação de serviço. Também, para saber como a organização reage com as reclamações, de forma que seja possível relacionar esses aspectos com a satisfação e a lealdade da população para a utilização do serviço.

No decorrer do trabalho, apresentar-se-á uma breve descrição sobre a satisfação de clientes e as relações existentes entre os constructos apresentados. Esses atributos fazem parte do Índice Europeu de Satisfação do Consumidor - modelo utilizado European Customer Satisfaction Index (ECSI). Quanto à metodologia utilizada no trabalho, foi efetuada uma pesquisa quantitativa descritiva, definindo-se ainda como de levantamento, na qual foram aplicados questionários (survey) aos usuários do SER. Como método multivariado, utilizou-se o Partial Least Squares-Path Modeling (PLS-PM). Por fim, foram apresentados os resultados e as considerações finais da pesquisa. 


\section{Cenário atual da mobilidade urbana}

Muitos são os esforços no sentido de colaborar com pesquisas sobre a mobilidade urbana. No Brasil, destacam-se trabalhos de autores como Silveira (2004), Costa (2003), Pontes (2010), Vasconcellos (2005), entre outros. Na conotação convencional, para Silveira (2004), a mobilidade, visualizada por meio de uma abordagem quantitativa, representa os deslocamentos ou viagens que ocorrem no contexto da cidade e que têm como referência um ponto de origem e outro de destino no espaço. Pontes (2010) aponta que a mobilidade é muito mais um termo qualitativo do que quantitativo, uma vez que está relacionada à capacidade de uma pessoa ou de um grupo de pessoas para se deslocar. Essa capacidade é determinada por uma série de fatores, como a localização das atividades, a capacidades física e financeira para o deslocamento, entre outras. Com relação ao termo mobilidade, Vasconcellos (2005) visualiza que os habitantes das cidades possuem necessidades e diversos motivos para realizar seus deslocamentos diários, seja para o trabalho, para tratar questões de saúde, estudo, lazer etc. Nesses trajetos, diferem-se os meios utilizados para o transporte, estando diretamente relacionados às questões físicas, pessoais, bem como à capacidade de pagamento e à disponibilidade de tempo e da oferta dos meios de transporte. A mobilidade urbana é um atributo das cidades, relativo ao deslocamento de pessoas e bens no espaço urbano, utilizando para isso veículos, vias e toda a infraestrutura urbana (Brasil, 2007).

Partindo do exposto e da necessidade de prover a todo cidadão condições de acessibilidade às zonas de interesse coletivo, a preocupação com a crise da mobilidade urbana e metropolitana proporcionou condições ideais para a aprovação da Lei Federal no 12.587/2012 (Brasil, 2012), que instituiu a nova política nacional de mobilidade urbana. A lei objetiva contribuir para o acesso universal à cidade, estabelecendo que as condições para os deslocamentos das pessoas e bens estejam relacionadas ao desenvolvimento urbano e à melhoria do transporte público, conforme aponta a Frente Nacional dos Prefeitos (FNP, 2012).

Analisando a preocupação com a crise da mobilidade urbana, podem ser destacados alguns problemas e apontadas soluções para a melhoria desse cenário.

Com relação à crise, observa-se a falta de planejamento das cidades no que tange à mobilidade - referente aos deslocamentos - e à acessibilidade - possibilidade aos cidadãos de atingirem os destinos desejados. Com essa situação percebe-se falta de qualidade de vida nas cidades pelas políticas implantadas, aumento de acidentes de trânsito, poluição, estresse causado por demorados deslocamentos dos veículos (FNP, 2012).

No entendimento de Costa (2003), realizando uma análise do termo mobilidade urbana no Brasil, quando comparado com outros países, por exemplo, Portugal, aponta que ainda é pouco estruturado esse setor, uma vez que a carência de dados e de informações apresenta-se como um dos principais problemas.

Como forma de amenizar a situação, aponta-se a possibilidade de ser revertido o atual modelo de mobilidade, integrando-o aos instrumentos de gestão urbanística, devendo a temática ser tratada como uma abordagem multidisciplinar, e não a partir de elementos isolados (Brasil, 2007). Em uma nova visão, Assis (2010) visualiza que a solução está na quarta dimensão das cidades, na qual os serviços de utilidades públicas e transportes devem ser predominantemente subterrâneos, auxiliados por novas tecnologias, tendo por objetivo direcionar as cidades para pessoas, moradia, trabalho, lazer. Já Elias (2001) expõe estratégias adotadas por órgãos públicos para a maior qualidade de vida nas cidades, como a implantação de espaço dissuasório e de estacionamento rotativo. Na primeira situação, gestores implantam estacionamentos públicos em áreas próprias, perto do perímetro central e de terminais intermodais (por exemplo, transportes coletivos), de forma que o condutor seja motivado a estacionar o veículo e a seguir seu trajeto por meio de transportes coletivos. Já os estacionamentos rotativos se estabelecem em reservas de áreas, definidas pela autoridade de trânsito e regulamentadas com horários e valores.

Por fim, Araújo (2013) expõe uma medida que o poder público deve adotar para viabilizar a mobilidade urbana e o acesso da coletividade aos locais de grande fluxo de veículos e pessoas. Ele orienta, então, a necessidade de se regulamentar o estacionamento de veículos em determinadas áreas, obrigando a rotatividade de vagas, principalmente nos municípios em que a frota automobilística tenha crescido. Dessa forma, o autor justifica a implantação de estacionamentos rotativos a fim de suavizar a relação do impasse gerado entre o crescimento da demanda de veículos por vagas e a escassez dos espaços urbanos. 
Implantação do sistema de Estacionamento Rotativo (SER) e as políticas de gestão e de regulamentação

Acompanhando a realidade mundial, em que especialistas alertam sobre a grave crise de mobilidade urbana, observou-se a necessidade de melhor regulamentar a circulação de veículos no centro da cidade de Bagé, o qual também coincide com o centro comercial.

Diante do crescente volume anual de veículos em circulação nos municípios - uma realidade também em Bagé - buscaram-se ações que apontassem para a qualificação dos deslocamentos na cidade. Naquele momento, realizaram-se estudos e visitas técnicas a outros municípios com o objetivo de conhecer ações já realizadas para a adequação desse setor. Assim, em 2010 foi planejado e, em 2011, implantado o SER em Bagé.

O serviço, previsto na Lei Federal nº 9.503/1997, e que institui o Código de Trânsito Brasileiro (CTB), regulamentado pelo poder público municipal por meio da criação da Lei no 4.893/2010, que autoriza a implantação de áreas de estacionamento rotativo pago nas ruas centrais da cidade, consiste em regulamentar, monitorar e fiscalizar vagas de estacionamento rotativo (Brasil, 2008).

Araújo (2013) aponta a implantação desses sistemas como uma previsão legislativa (artigo 24, inciso X do CTB), tratando-se de um serviço público, de titularidade dos municípios integrados ao Sistema Nacional de Trânsito, podendo ser objeto de concessão a empresas privadas, conforme artigos 30 , inciso $\mathrm{V}$, e 175 da Constituição Federal de 1988, e regido por regras de direito público. Ainda, cita-se o Código Civil (Lei no 10.406/2002), que aponta no artigo 103 que

[...] o uso comum dos bens públicos pode ser gratuito ou retribuído, conforme for estabelecido legalmente pela entidade a cuja administração pertencerem (Brasil, 2002, p. 27).

Para tanto, legalmente estabelecidas, as vagas passaram a ser controladas pelo poder executivo municipal por intermédio da Secretaria de Transportes e Circulação, representada pela Coordenadoria de Estacionamento Rotativo, que, com competência administrativa, concentrou-se na prestação do serviço público de implantação, manutenção e operação do SER.

A equipe de trabalho no setor está composta por um coordenador, dois supervisores externos - que são servidores celetistas e agentes da autoridade de trânsito competentes para lavrar o auto de infração de trânsito - e quinze monitores de estacionamento rotativo, admitidos por meio de contrato administrativo temporário, que possuem a função de efetuar o monitoramento e a cobrança aos condutores de veículos automotores pela utilização compartilhada de 600 vagas de estacionamento localizadas no perímetro central, nas principais vias que apresentaram necessidade de implantação do sistema.

Para a identificação desses locais, levou-se em consideração o desenvolvimento de estudos de viabilidade de implantação desse tipo de sistema, para que fosse possível identificar a demanda. Na análise, verificaram-se alguns itens, tais como a área de influência das atividades locais (comércio, serviços e outros), o nível de concentração dessas atividades (levantamento do uso do solo), as origens dos problemas de trânsito (se eles ocorrem devido à disputa de vagas ou acesso a elas), o motivo do estacionamento nas vias da região (polos de atração), identificação das características e horários de funcionamento dos estabelecimentos comerciais, a metragem linear de meio-fio disponível para disposição de vagas de estacionamento, entre outros aspectos (Elias, 2001).

O serviço consiste em monitorar e fiscalizar a utilização rotativa das vagas de estacionamento. Para o uso do espaço regulamentado, definido popularmente como área azul, os condutores efetuam o pagamento de $\mathrm{R} \$ 0,75$ (setenta e cinco centavos) pelo tempo de meia hora estacionados na vaga, podendo permanecer pelo período máximo de duas horas (o valor pago aumenta conforme o tempo estacionado). Para aquisição dos créditos, os condutores precisam realizar a compra do cartão de estacionamento, modelo raspadinha, vendido em estabelecimentos comerciais identificados no centro da cidade.

Em conformidade com o exposto, Araújo (2013) aponta que, além da rotatividade, a legislação deve prever a necessidade de pagamento pela vaga utilizada pelo veículo a fim de criar um estímulo negativo para o estacionamento na via pública. 0 autor afirma que

[...] não basta trocar o veículo de vaga, mas a ideia é possibilitar que todos os que necessitam da vaga de estacionamento na via possam dela utilizar, de forma democrática e igualitária (Araújo, 2013, p. 1).

Nesse sentido, aponta-se que demais disposições que regulam e normatizam o funcionamento do sistema 
em espaço público, assim como previsão legal para a cobrança por meio de preço público, constem em decretos e na legislação municipal.

\section{Mensuração da satisfação de usuários de serviços}

Diferentes estudos demonstram existir uma forte relação positiva quanto aos fatores satisfação e propensão de lealdade de clientes. Investir em clientes, tornando-os satisfeitos e fiéis à utilização de um serviço ou produto, gera retorno econômico, podendo ser medido por diferentes formas, como por meio do retorno sobre investimentos, valor agregado, entre outros. Com isso, observa-se uma forte relação entre os fatores satisfação, lealdade e desempenho econômico. Baseados nessas questões é que surgiram metodologias diferentes, a exemplo do ECSI, capaz de medir a satisfação de clientes e a propensão destes à lealdade (Edvardsson et al., 2000; Fornell, 1992).

Índice Europeu de Satisfação do Consumidor (ECSI)
Instituições europeias definiram as bases para o lançamento do projeto-piloto do Índice Europeu de Satisfação de Cliente, designado como European Customer Satisfaction Index - (ECSI) (Leite \& Gonçalves, 2007).

O objetivo central do ECSI foi o de desenvolver um instrumento de mensuração da satisfação do cliente mais adequado ao mercado europeu (Lopes et al., 2009). 0 modelo disponibiliza, entre outros aspectos: a comunicação entre os seus clientes, colaboradores e acionistas; defende interesses entre as partes envolvidas; oportuniza avaliação dos processos e melhoria da qualidade; constrói uma plataforma para análise da organização; contribui para a competitividade e o desenvolvimento econômico (ECSI, 2013).

0 índice de satisfação do cliente, conforme apresentado na Figura 1, é explicado por quatro antecedentes - imagem, expectativas dos clientes, qualidade e valor percebido - e por dois consequentes - reclamações e lealdade.

Portanto, a sistemática portuguesa contempla sete variáveis do modelo estrutural que são variáveis latentes (VL) e não podem servir como objeto de observação direta (Quadro 1). Devem ser associadas a um conjunto de indicadores (variáveis de medida),

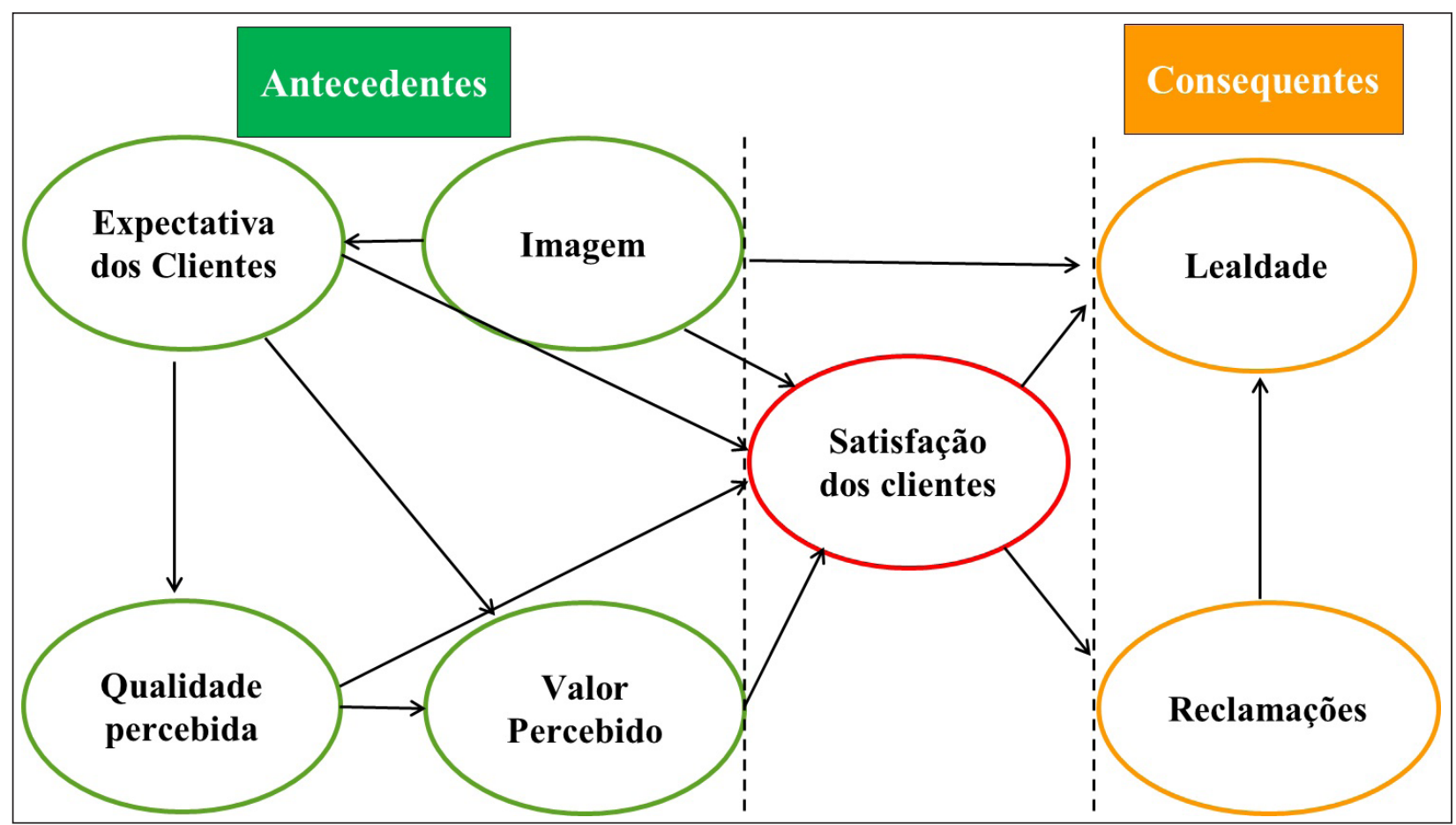

Figura 1 - Modelo estrutural da satisfaç̃̃o dos clientes (ECSI) Fonte: Adaptado de Tenenhaus et al. (2005). 
Quadro 1 - Definição das variáveis latentes (VL) de acordo com diferentes autores

\begin{tabular}{|c|c|}
\hline Variáveis latentes (VL) & Definição das variáveis latentes (VL) na concepção de autores \\
\hline Satisfação & $\begin{array}{l}\text { Aspecto de sensacão de prazer ou desapontamento resultante da comparação do desempenho percebido em relação às expectativas do } \\
\text { comprador (Kotler, 2000). }\end{array}$ \\
\hline Expectativa & $\begin{array}{l}\text { Qualidade que os clientes esperam encontrar em produtos ou servicos e que venham a ưtilizar ou consumir (Gianesi \& Corrêa, 1994), } \\
\text { Expectativas incluem não só a informação que os clientes detinham no passado sobre os produtos e servicos oferecidos, mas, igualmente, } \\
\text { a antecipação sobre a capacidade de a empresa oferecer, no futuro, produtos e serviços com qualidade (ECSI, 2013). }\end{array}$ \\
\hline Qualidade & $\begin{array}{l}\text { Análise com relacão à excelência de produtos/servicos disponibilizados pela empresa. Percebida para além de um julgamento global, a a } \\
\text { qualidade integra a avaliaccão sobre um conjunto de dimensōes (ECSI, 2013). Aspecto que faz a empresa investir fortemente em técnicas } \\
\text { que conduzem à qualidade para haver maior aperfeiçoamento de produtos e servicuss, além da satisfação de clientes (Silva, 2005). }\end{array}$ \\
\hline Imagem & $\begin{array}{l}\text { É um conjunto de ideias, sentimentos e atitudes que o cliente tem sobre o produto (Toni \& Schuler, 2007). Se os compradores de umo } \\
\text { empresa acreditam que esta é confível, irõo desenvolver uma imagem positiva desse ambiente e serem os protagonistas da propaganda) } \\
\text { interpessoal favorável. Com isso, influenciam o valor percebido e, consequentemente, a satisfação dos futuros clientes (Kristensen et al., 2000). }\end{array}$ \\
\hline Valor percebido & 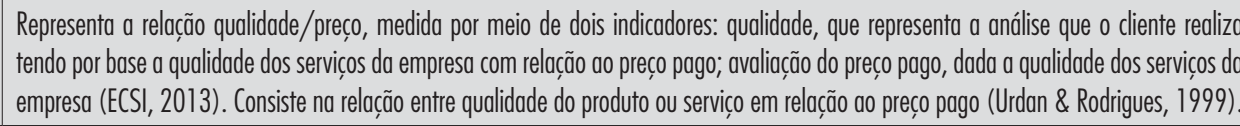 \\
\hline Lealdade & 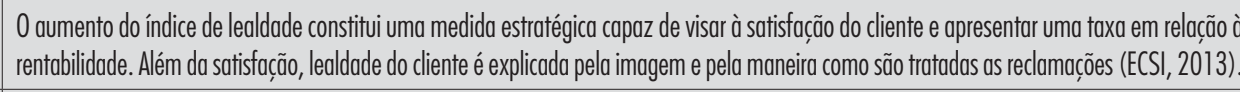 \\
\hline Reclamação & 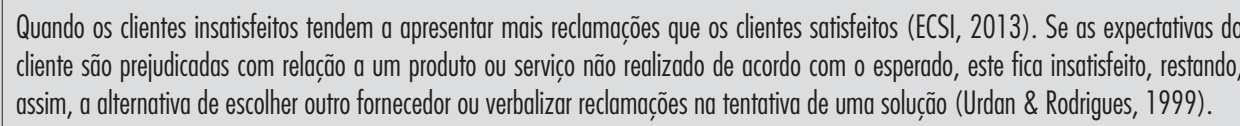 \\
\hline
\end{tabular}

Fonte: Elaborado pelos autores (2014).

obtidos por meio da aplicação de questionário com os clientes (ECSI, 2013).

Para elucidar o exposto, destacam-se alguns trabalhos realizados utilizando como sistemática de mensuração o modelo ECSI. 0 trabalho de Leite \& Gonçalves (2007), por exemplo, foi realizado em uma empresa fornecedora de softwares Enterprise Resource Planning (ERP). No entanto, houve uma adaptação do modelo original, na qual o constructo reclamação foi retirado da pesquisa. Os resultados apontaram para um bom ajuste do modelo, mas deve-se ressaltar que a reclamação foi excluída sem uma justificativa teórica, e a satisfação foi mensurada com apenas dois indicadores.

Ceretta \& Righi (2012) também utilizaram o modelo ECSI, buscando mensurar as relações que envolvem a satisfação dos clientes de telefonia celular. Os resultados obtidos permitiram concluir que os constructos de qualidade percebida e de valor percebido apresentaram maior impacto na formação da satisfação dos clientes. Além disso, foi verificado que a satisfação dos clientes é o principal fator responsável pela formação da lealdade destes, seguido por reclamações e imagem.
Ainda, podem-se destacar outros trabalhos, tais como Urdan \& Rodrigues (1999), Pereira da Silva (2005), Bennet \& Rundle-Tiele (2004), Bloemer \& Odekerken-Schroder (2002) e Olsen (2002), que versam sobre a avaliação de serviços.

\section{Metodologia do estudo}

\section{Método e tipo de pesquisa adotada}

Desenvolveu-se um estudo tendo por base uma pesquisa quantitativa descritiva, definindo-se ainda como de levantamento, com os usuários do SER do município de Bagé.

Para realizar a pesquisa, utilizou-se o método multivariado PLS-PM, além dos construtos que podem ser observados no Quadro 2, definidos como VL e suas respectivas variáveis manifestas (VM). Essa técnica consiste em um modelo que liga uma variável dependente $\mathrm{Y}$ a um conjunto $\mathrm{X}$ de variáveis explanatórias numéricas ou nominais (Bastien et al., 2015).

Tenenhaus et al. (2005) enfatizam que a forma do modelo PLS-PM é descrita por meio de dois modelos: 
Quadro 2 - Constructos e questões do questionário

\begin{tabular}{|c|c|}
\hline $\begin{array}{l}\text { Constructos } \\
\text { Variáveis latentes } \\
\text { (VL) }\end{array}$ & $\begin{array}{c}\text { Variáveis observáveis - Variáveis manifestas (VM) } \\
\text { (Perguntas realizadas aos usuários do Sistema de Estacionamento } \\
\text { Rotativo - SER) }\end{array}$ \\
\hline Qualidade & 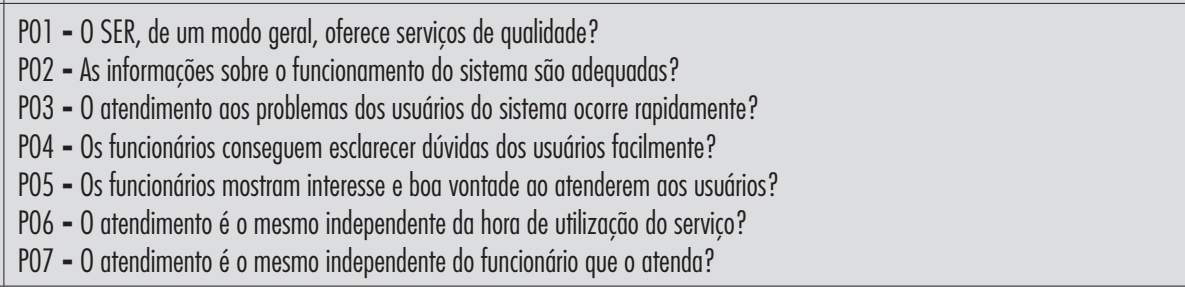 \\
\hline Valor percebido & $\begin{array}{l}\text { P08 - Considerando as características do serviço, o estacionamento vale o que você paga? } \\
\text { P09 - Considerando os precos cobrados, você classifica a qualidade do servico adequada? } \\
\text { P10 - Levando em conta a qualidade do serviço prestado, você avalia como ideal? } \\
\text { P1 - A boa vontade dos funcionários em atender aos clientes compensa o que você paga? }\end{array}$ \\
\hline Imagem & 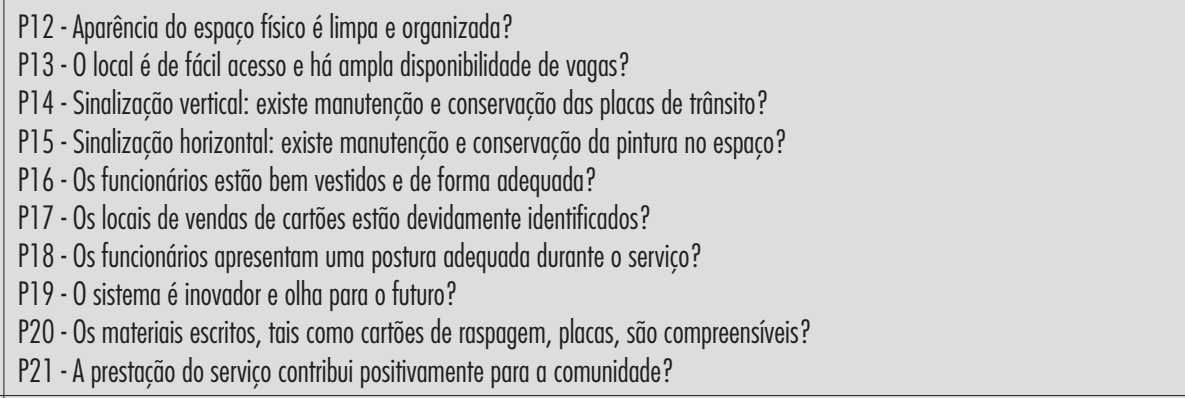 \\
\hline Expectativa & $\begin{array}{l}\text { P22 - Quando me tornei cliente, achava que minhas necessidades fossem ser atendidas? } \\
\text { P23 - Quando me tornei usuário do sistema, achava que os servicos iriam me satisfazer? } \\
\text { P24 - No geral, o sistema mostrou ser exatamente aquilo que eu esperava? } \\
\text { P25 - Eu tinha expectativa elevada quanto à qualidade do serviço?? } \\
\text { P26 - Ao me tornar usuário, esperava ser atendido com atençāo e educacaçõo? }\end{array}$ \\
\hline Satisfação & $\begin{array}{l}\text { P27 - Quanto aos servicos prestados, atendem plenamente às minhas necessidades? } \\
\text { P28 - Os servicos prestados são confiáveis? } \\
\text { P29 - Tem sido bom, para mim, utilizar os serviços prestados no sistema? } \\
\text { P30 - De um modo geral, eu me sinto totalmente satisfeito com o sistema rotativo? }\end{array}$ \\
\hline Lealdade & $\begin{array}{l}\text { P31 - O SER será sua primeira lembrança quando necessitar desse tipo de serviçọ? } \\
\text { P32 - Você recomenda e falaria bem do estacionamento para outras pessoas? } \\
\text { P33 - Você tem a intenção de procurar empresas que prestem servicosos semelhantes? } \\
\text { P34 - Você pretende continuar sendo usuário do estacionamento rotativo? }\end{array}$ \\
\hline Reclamação & 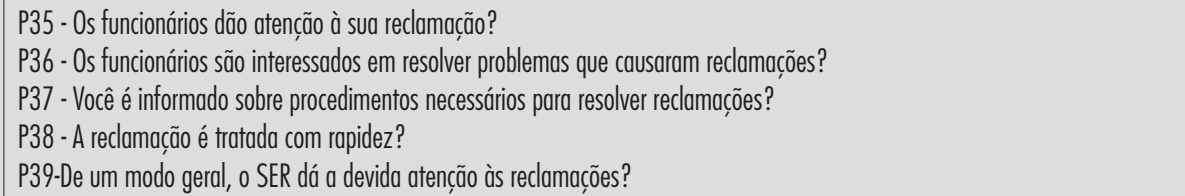 \\
\hline
\end{tabular}

Legenda: $\mathrm{Pl}, \mathrm{P2}, \mathrm{P3} \ldots \mathrm{Pn}=$ perguntas do questionário.

Fonte: Adaptado de Tenenhaus et al. (2005).

i) um modelo de medição (externo), que relaciona as variáveis observáveis (as VM) com seus construtos (as VL); ii) um modelo estrutural (interno), que relaciona construtos exógenos a endógenos. Um construto é uma variável não observável descrita indiretamente por um bloco de variáveis observáveis ou indicadores. As VM podem se relacionar com seus construtos tanto de uma maneira refletiva, isto é, sendo consequência deles, como de maneira formativa, agindo como antecedente deles.

Indicadores de produto refletindo a interação dos construtos (VL) são criados. Cada conjunto de variáveis observáveis que refletem seu construto subjacente é apresentado ao PLS-PM para a estimativa, o que resulta 
em uma avaliação mais precisa das VL subjacentes e de seus relacionamentos (Chin et al., 1996).

Verificando a confiabilidade dos blocos de VM, utilizaram-se como medida quantitativa, o Alfa de Cronbach e o Rho de Dillon-Goldstein. Segundo Tenenhaus et al. (2005), um bloco é considerado unidimensional quando esses dois índices forem maior que 0,7. Já Chin (1998) destaca com ênfase que o Rho de Dillon-Goldstein é considerado melhor indicador de unidimensionalidade de um bloco do que o Alfa de Cronbach.

A validação do modelo PLS-PM proposta por Tenenhaus et al. (2005) consiste em três etapas: i) qualidade do modelo de medição, ii) qualidade do modelo estrutural e iii) significância das equações de regressão do modelo estrutural. A fim de medir a qualidade do modelo de medição para cada bloco, o índice utilizado foi a comunalidade, definida como uma média de todas as correlações ao quadrado das VM com sua respectiva VL.

No entanto, o índice de redundância mensurou a qualidade do modelo estrutural para cada VL endógena, levando em conta o modelo de medição. 0 índice foi definido para um constructo endógeno j como $\operatorname{cor}^{2}\left(\mathrm{VM}_{\mathrm{ji}}, \mathrm{VL}_{\mathrm{j}}\right) * \mathrm{R}^{2}\left(\mathrm{VL}_{\mathrm{j}} \leftarrow \mathrm{VL}_{\mathrm{i}}\right)$. Diferentemente da modelagem de equações estruturais, o PLS-PM não otimiza uma função global escalar, de modo que naturalmente carece de um índice que possa fornecer ao usuário uma validação global do modelo.

Uma solução operacional para esse problema é o critério global de qualidade de ajuste - Goodness of-fit (GoF) - que, segundo Amato et al. (2004), pode ser definido como a média geométrica entre a comunalidade média e o $\mathrm{R}^{2}$ médio das regressões estruturais. Tal índice possui valor que varia de 0 e 1 . Quanto mais perto de 1, melhor o ajuste do modelo. Portanto, para a validação global do modelo, foi utilizado GoF, como já definido.

Instrumento de coleta de dados

Para coleta de dados, aplicaram-se questionários aos usuários do SER, de forma não aleatória, em locais e horários de funcionamento da área rotativa, no mês de janeiro de 2014.

O instrumento utilizado para a coleta de dados da pesquisa foi um questionário com perguntas fechadas, com opções de respostas de múltipla escolha. Essa ferramenta foi dividida em duas seções: a primeira com 14 questões, que analisou o perfil do respondente, e a segunda com 39 itens (escala tipo Likert). Foi utilizada uma convenção na qual os usuários puderam responder a cada questão optando por um valor de 1 (discordo totalmente/negativo) a 10 (concordo totalmente/positivo). Na questão 40, realizada por meio de uma pergunta aberta, buscou-se identificar sugestões e reclamações do usuário.

\section{População, amostra, tratamento} e análise dos dados

A população correspondeu aos usuários do SER, e a amostra, à parte desse público que foi abordado (de forma não aleatória) para aplicação do questionário. Assim, foram respondidos dez questionários para cada questão realizada de um total de 40 questões, totalizando uma amostra de 401 questionários válidos.

Quanto ao tamanho da amostra, Hair et al. (2009) expõem que deve conter, como regra geral, no mínimo cinco vezes mais observações do que o número de variáveis a serem analisadas, e o tamanho mais aceitável teria uma proporção de dez para um.

Realizou-se um tratamento quantitativo nos dados segundo o método estatístico conhecido como análise fatorial. Para a tabulação, utilizou-se planilha do Excel, e, para a análise, o software R.

\section{Resultados da pesquisa}

Os resultados apresentam-se por categoria de análise: perfil dos entrevistados, modelo de satisfação do usuário e análise de diferenças por grupo (Kruskal Wallis).

\section{Perfil dos entrevistados}

Inicialmente, foi observado o perfil dos respondentes, conforme apresenta a Tabela 1.

As variáveis analisadas foram gênero, faixa etária, renda, escolaridade, atividade profissional, cidade de origem e o local da residência do usuário do sistema no município. De forma geral, essas variáveis buscaram caracterizar o usuário que utiliza o SER no município de Bagé. 
Tabela 1 - Perfil dos entrevistados

\begin{tabular}{|c|c|c|c|c|}
\hline \multirow{2}{*}{ Variáveis } & \multirow{2}{*}{ Opções de respostas } & \multicolumn{3}{|c|}{ Frequência } \\
\hline & & Total & $\%$ & \% válida \\
\hline \multirow{2}{*}{ Gênero } & Masculino & 238 & 59,4 & 60,4 \\
\hline & Feminino & 156 & 38,9 & 39,6 \\
\hline \multirow{6}{*}{ Faixa etária } & De 18 a 25 anos & 62 & 15,5 & 15,7 \\
\hline & De 26 a 35 anos & 145 & 36,2 & 36,7 \\
\hline & De 36 a 45 anos & 86 & 21,4 & 21,8 \\
\hline & De 46 a 55 anos & 62 & 15,5 & 15,7 \\
\hline & De 56 a 65 anos & 26 & 6,5 & 6,6 \\
\hline & Mais de 65 anos & 14 & 3,5 & 3,5 \\
\hline \multirow{5}{*}{ Renda } & Até $R \$ 678,00$ & 33 & 8,2 & 8,5 \\
\hline & Mais de $R \$ 678,00$ até $R \$ 2.000,00$ & 190 & 47,4 & 48,7 \\
\hline & Mais de $\mathrm{R} \$ 2.000,00$ até $\mathrm{R} \$ 4.000,00$ & 109 & 27,2 & 27,9 \\
\hline & Mais de $R \$ 4.000,00$ até $R \$ 6.000,00$ & 39 & 9,7 & 10,0 \\
\hline & Mais de $R \$ 6.000,00$ & 19 & 4,7 & 4,9 \\
\hline \multirow{9}{*}{ Escolaridade } & $1^{0}$ grau $\left(1^{0}\right.$ a $8^{0}$ série) incompleto & 14 & 3,5 & 3,5 \\
\hline & $1^{0}$ grau $\left(1^{0}\right.$ a $8^{0}$ série) completo & 9 & 2,2 & 2,3 \\
\hline & $2^{\circ}$ grau (ensino médio) incompleto & 20 & 5,0 & 5,0 \\
\hline & $2^{0}$ grau (ensino médio) completo & 101 & 25,2 & 25,3 \\
\hline & Superior incompleto & 126 & 31,4 & 31,6 \\
\hline & Superior completo & 71 & 17,7 & 17,8 \\
\hline & Especialização (pós-graduaç̦̃o) & 43 & 10,7 & 10,8 \\
\hline & Mestrado & 13 & 3,2 & 3,3 \\
\hline & Doutorado & 2 & 0,5 & 0,5 \\
\hline \multirow{4}{*}{ Atividade profissional } & Autônomo & 85 & 21,2 & 21,9 \\
\hline & Servidor público & 137 & 34,2 & 35,2 \\
\hline & Empregado setor privado & 139 & 34,7 & 35,7 \\
\hline & Empregador & 28 & 7,0 & 7,2 \\
\hline \multirow{3}{*}{$\begin{array}{c}\text { Local da residência no } \\
\text { município }\end{array}$} & Zona urbana centro & 171 & 42,6 & 43,1 \\
\hline & Zona urbana bairro & 218 & 54,4 & 54,9 \\
\hline & Zona rural & 8 & 2,0 & 2,0 \\
\hline \multirow{3}{*}{ Cidade de origem } & Bagé & 365 & 91,0 & 95,1 \\
\hline & Outra cidade & 19 & 4,7 & 4,9 \\
\hline & Total & 401 & & $100 \%$ \\
\hline
\end{tabular}

Fonte: Dados da pesquisa (2014).

Em relação ao perfil dos respondentes, foi possível observar, na Tabela 1, alguns dados que mereceram comentários. Os usuários do SER, na maioria, são do gênero masculino $(60,4 \%)$, enquanto que o gênero feminino corresponde a $39,6 \%$, o que permite concluir que as mulheres se encontram em número inferior aos homens enquanto usuárias do SER. Relativo à faixa etária dos respondentes, constata-se que $58,5 \%(36,6 \%+21,8 \%)$ dos usuários possuem idades entre 26 e 45 anos. Quanto à renda, percebe-se que aproximadamente a metade dos usuários $(48,7 \%)$ possui renda de um a três salários mínimos. No que 
se refere à escolaridade, $31,6 \%$ dos usuários possuem ensino superior incompleto. Também se observa que, com percentuais muito próximos, mais da metade dos usuários está inclusa enquanto profissão nas opções de servidores públicos (35,2\%) e empregados do setor privado $(35,7 \%)$.

Na Tabela 1, curiosamente, observa-se ainda um dado interessante a ser destacado: que $43,1 \%$ dos usuários do sistema se originam do centro da cidade (residem), e 54,9\%, dos bairros. Isso permite confirmar a dificuldade na disponibilização e compartilhamento de vagas de estacionamento, uma vez que o sistema está instalado em vias centrais da cidade, e parte da população identificou-se em um percentual significativo como usuários que utilizam o sistema e, ao mesmo tempo, concentram suas residências na área central da cidade. Percebe-se ainda que quase a totalidade dos usuários é pertencente ao município de Bagé $(95,1 \%)$.

Na Tabela 2, são apresentadas as características e os aspectos relacionados aos usuários do SER,

Tabela 2 - Caracterização dos respondentes quanto à forma de utilização do sistema de estacionamento rotativo

\begin{tabular}{|c|c|c|c|c|}
\hline \multirow{2}{*}{ Variáveis } & \multirow{2}{*}{ Opções de respostas } & \multicolumn{3}{|c|}{ Frequência } \\
\hline & & Frequência & $\%$ & \% válida \\
\hline \multirow{5}{*}{$\begin{array}{c}\text { Principal forma de } \\
\text { deslocamento na cidade }\end{array}$} & De carro & 352 & 87,8 & 89,1 \\
\hline & De motocicleta & 23 & 5,7 & 5,8 \\
\hline & De ônibus & 10 & 2,5 & 2,5 \\
\hline & De bicicleta & 2 & 0,5 & 0,5 \\
\hline & Outro & 8 & 2,0 & 2,0 \\
\hline \multirow{5}{*}{ Frequência que utiliza o sistema } & Uma a três vezes por mês & 141 & 35,2 & 35,2 \\
\hline & Uma ou duas vezes na semana & 134 & 33,4 & 33,4 \\
\hline & Três a cinco vezes na semana & 82 & 20,4 & 20,4 \\
\hline & Todos os dias da semana & 27 & 6,7 & 6,7 \\
\hline & Esporadicamente & 17 & 4,2 & 4,2 \\
\hline \multirow{4}{*}{ Motivo pelo qual utiliza o sistema } & Oportuniza acesso às vagas & 117 & 29,2 & 29,8 \\
\hline & Gera sensação de segurança & 16 & 4,0 & 4,1 \\
\hline & Evita ficar à procura de vagas & 115 & 28,7 & 29,3 \\
\hline & Todas as opções anteriores & 145 & 36,2 & 36,9 \\
\hline \multirow{2}{*}{ Quanto à implantação do sistema } & Foi positiva a implantação & 337 & 84,0 & 86,0 \\
\hline & Preferia que não existisse o SER & 55 & 13,7 & 14,0 \\
\hline \multirow{2}{*}{ Quanto à necessidade de expansão } & Usuário favorável à expansão & 230 & 57,4 & 61,2 \\
\hline & Usuário desfavorável à expansão & 146 & 36,4 & 38,8 \\
\hline \multirow{4}{*}{$\begin{array}{l}\text { Quanto à utilização: o usuário } \\
\text { utiliza o sistema quando está }\end{array}$} & Realizando compras & 127 & 31,7 & 33,2 \\
\hline & A passeio & 99 & 24,7 & 25,9 \\
\hline & A trabaho & 19 & 4,7 & 5,0 \\
\hline & Em compromisso particular & 137 & 34,2 & 35,9 \\
\hline \multirow{2}{*}{ Tipo de vaga utilizada pelo usuário } & Vaga paga (área azul e verde) & 376 & 93,8 & 96,4 \\
\hline & Vaga nõo paga (ex.: idosos etc.) & 14 & 3,5 & 3,6 \\
\hline Total & & 401 & & $100 \%$ \\
\hline
\end{tabular}

Fonte: Dados da pesquisa (2013). 
tais como a forma de deslocamento pela cidade, a frequência de utilização do sistema, o motivo pelo qual utilizam, a conformidade com relação à implantação do sistema, a percepção sobre a necessidade de expansão, a finalidade de utilização do sistema e o tipo de vaga utilizada.

De acordo com o apresentado na Tabela 2, parte considerável dos usuários realiza seus deslocamentos diários utilizando veículos automotores individuais $(89,1 \%)$, fator esse que corrobora a falta de oferta de vagas no centro da cidade. Observa-se também que $35,2 \%$ dos condutores de veículos utilizam o sistema de uma a três vezes por mês e, em percentual aproximado, 33,4\% utilizam o sistema uma ou duas vezes na semana. Relativo ao motivo pelo qual o usuário utiliza o SER, constata-se que a maior parcela $(36,9 \%)$ aponta todos os benefícios (acesso às vagas, facilidade do estacionamento, evitar a busca por vagas e sensação de segurança). Quanto à implantação do SER na cidade de Bagé, identificou-se que a grande maioria dos entrevistados (86\%) indica que a implantação do sistema na cidade foi positiva, e 61,2\% dos usuários relatam ser favorável à expansão do sistema para demais quadras centrais da cidade.

Em análise da Tabela 2, quanto à necessidade de utilização do sistema, dois itens foram principalmente apontados: os compromissos particulares $(35,9 \%)$ e a realização de compras $(33,2 \%)$. Do total de entrevistados, $96,4 \%$ que utilizam o sistema pagam o valor correspondente ao tempo de utilização da vaga, fixado por decreto, e apenas 3,6\%, apontam utilizar vagas não pagas, estando inclusas, entre estas, vagas especiais para veículos conduzidos ou que transportam pessoas idosas e/ou pessoas portadores de necessidades especiais (PNE), veículos oficiais, de emergência, em prestação de serviços de utilidade pública (placa branca), entre outros.

\section{Modelo de satisfação do usuário do sistema de estacionamento rotativo}

Na Tabela 3, apresentam-se indicadores básicos para cada um dos sete constructos (imagem, expectativa, qualidade, valor, satisfação, lealdade e reclamações).

Identificou-se, na Tabela 3, que a estatística Alfa de Cronbach calculada para todos os constructos foi superior a 0,900, assim como o Rho de Dillon-Goldstein, indicando a presença de confiabilidade nessas VL. Foram identificados os dois altos valores de maior importância dentro de cada constructo, no qual se constata a unidimensionalidade, pois somente o primeiro autovalor é superior a 1, e o segundo, autovalor 2 , sempre inferior a 1 .

Na Tabela 4, apresentam-se valores que resumem a qualidade do modelo interno aplicado.

Conforme pode ser observado na Tabela 4, na segunda e terceira coluna, respectivamente, aparecem a classificação de cada constructo (exógeno/endógeno/ reflexivo) e o número de variáveis observadas que o constituem. Na quarta, quinta e sexta coluna, há os indicadores de ajuste $\mathrm{R}^{2}$, redundância média e variância média extraída, respectivamente. Os valores atestam para a validade do modelo, pois, além de elevado coeficiente de determinação, tem-se associada, para cada constructo, uma variância média extraída superior

Tabela 3 - Confiabilidade e unidimensionalidade das varíaveis latentes (VL)

\begin{tabular}{ccccccc}
\hline $\begin{array}{c}\text { Variável } \\
\text { latente (VL) }\end{array}$ & Modelo & VM & $\begin{array}{c}\text { Alpha de } \\
\text { Cronbach }\end{array}$ & RHO D. G. & Autovalor I & Autovalor 2 \\
\hline Imagem & Reflexivo & 8 & 0,914 & 0,930 & 5,00 & 0,740 \\
Expectativa & Reflexivo & 5 & 0,905 & 0,930 & 3,64 & 0,542 \\
Qualidade & Reflexivo & 7 & 0,929 & 0,943 & 4,91 & 0,671 \\
Valor & Reflexivo & 4 & 0,920 & 0,944 & 3,23 & 0,370 \\
Satisfaç̃ón & Reflexivo & 4 & 0,940 & 0,957 & 3,39 & 0,257 \\
Reclamaçã̃o & Reflexivo & 5 & 0,967 & 0,975 & 4,43 & 0,222 \\
Lealdade & Reflexivo & 3 & 0,917 & 0,948 & 2,57 & 0,262 \\
\hline
\end{tabular}

Fonte: Dados da pesquisa (2014). 
Tabela 4 - Avaliação do modelo

\begin{tabular}{cccccc}
\hline $\begin{array}{c}\text { Variável } \\
\text { latente (VL) }\end{array}$ & $\begin{array}{c}\text { Tipo de } \\
\text { modelo }\end{array}$ & $\mathbf{V M}$ & $\mathbf{R}^{\mathbf{2}}$ & $\begin{array}{c}\text { Redundância } \\
\text { média }\end{array}$ & $\begin{array}{c}\text { Variância } \\
\text { Média extraída }\end{array}$ \\
\hline Imagem & Exógeno Reflexivo & 8 & 0,000 & 0,000 & 0,621 \\
Expectativa & Endógeno Reflexivo & 5 & 0,522 & 0,378 & 0,724 \\
Qualidade & Endógeno Reflexivo & 7 & 0,423 & 0,296 & 0,701 \\
Valor & Endógeno Reflexivo & 4 & 0,580 & 0,468 & 0,807 \\
Satisfação & Endógeno Reflexivo & 4 & 0,778 & 0,659 & 0,847 \\
Reclamaç̃ón & Endógeno Reflexivo & 5 & 0,595 & 0,526 & 0,885 \\
Lealdade & Endógeno Reflexivo & 3 & 0,808 & 0,693 & 0,858 \\
\hline
\end{tabular}

Fonte: Dados da pesquisa (2014).

Tabela 5 - Efeitos diretos, indiretos e totais do modelo interno

\begin{tabular}{|c|c|c|c|c|}
\hline & Relações entre constructos & Efeito direto & Efeito indireto & Efeito total \\
\hline 1 & Imagem => expectativa & 0,722 & 0,000 & 0,722 \\
\hline 2 & Imagem $\Rightarrow>$ qualidade & 0,000 & 0,470 & 0,470 \\
\hline 3 & Imagem $\Rightarrow$ valor & 0,000 & 0,469 & 0,469 \\
\hline 4 & Imagem => satisfaçã̃o & 0,313 & 0,403 & 0,717 \\
\hline 5 & Imagem => redlamação & 0,000 & 0,553 & 0,553 \\
\hline 6 & Imagem $\Rightarrow>$ lealdade & 0,127 & 0,566 & 0,694 \\
\hline 7 & Expectativa $\Rightarrow>$ qualidade & 0,650 & 0,000 & 0,650 \\
\hline 8 & Expectativa $\Rightarrow>$ valor & 0,307 & 0,341 & 0,649 \\
\hline 9 & Expectativa $\Rightarrow>$ satisfação & 0,353 & 0,205 & 0,558 \\
\hline 10 & Expectativa $\Rightarrow>$ reclamação & 0,000 & 0,430 & 0,430 \\
\hline 11 & Expectativa $\Rightarrow>$ lealdade & 0,000 & 0,440 & 0,440 \\
\hline 12 & Qualidade $\Rightarrow>$ valor & 0,524 & 0,000 & 0,525 \\
\hline 13 & Qualidade $=>$ satisfação & 0,083 & 0,122 & 0,205 \\
\hline 14 & Qualidade $\Rightarrow>$ reclamação & 0,000 & 0,158 & 0,158 \\
\hline 15 & Qualidade $\Rightarrow>$ lealdade & 0,000 & 0,162 & 0,162 \\
\hline 16 & Valor $\Rightarrow>$ satisfação & 0,232 & 0,000 & 0,232 \\
\hline 17 & Valor => reclamação & 0,000 & 0,179 & 0,179 \\
\hline 18 & Valor $\Rightarrow>$ lealdade & 0,000 & 0,183 & 0,183 \\
\hline 19 & Satisfação => reclamação & 0,771 & 0,000 & 0,771 \\
\hline 20 & Satisfação $\Rightarrow>$ lealdade & 0,752 & 0,037 & 0,789 \\
\hline 21 & Reclamação $\Rightarrow>$ lealdade & 0,048 & 0,000 & 0,048 \\
\hline
\end{tabular}

Fonte: Dados da pesquisa (2014).

a 0,5. Para a análise da validação do modelo, os valores calculados para o GoF foram de 0,674 indicador de ajuste geral. Segundo Tenenhaus et al. (2005), valores de GoF próximos de 1 indicam perfeito ajustamento.
Na Tabela 5, pode ser visualizado que, em um modelo estrutural, existem relações claras entre os constructos, uma das quais chamada efeito direto, que mede o impacto imediato de um constructo sobre o outro. 
Tabela 6 - Estatísticas descritivas dos constructos

\begin{tabular}{ccccc}
\hline $\begin{array}{c}\text { Variáveis latentes } \\
\text { (VL) }\end{array}$ & Média & Desvio-padrão & Mínimo & Máximo \\
\hline Imagem & 7,26 & 1,80 & 1,75 & 10 \\
Expectativa & 7,40 & 1,73 & 1,00 & 10 \\
Qualidade & 7,31 & 1,82 & 1,00 & 10 \\
Valor & 6,73 & 2,36 & 1,00 & 10 \\
Satisfação & 7,65 & 2,06 & 1,00 & 10 \\
Reclamacẵo & 7,18 & 2,19 & 1,00 & 10 \\
Lealdade & 7,80 & 2,15 & 1,00 & 10 \\
\hline
\end{tabular}

Fonte: Dados da pesquisa (2014).

Assim, pode-se observar, na Tabela 5, que o efeito direto é apresentado com o efeito indireto de um constructo sobre o outro. Pode-se verificar, por exemplo, que a imagem tem um efeito indireto de 0,403 e um efeito direto de 0,313 sobre a satisfação, impactando positivamente. Esses dois efeitos totalizam um impacto de 0,717 . No entanto, os impactos diretos maiores estão na satisfação sobre a reclamação $(0,771)$ e na satisfação sobre a lealdade do usuário ao serviço $(0,752)$. Porém, a importância da imagem advém dos efeitos indiretos, ou seja, dos impactos exercidos sobre a lealdade $(0,555)$ e a qualidade $(0,470)$. Dessa forma, o efeito total maior, efeito direto e indireto, ocorreu na relação da variável satisfação dos usuários, que proporciona maior lealdade na utilização do sistema. Assim, fica caracterizada a importância de muitos constructos não pela sua ação direta, mas pelo seu impacto indireto na satisfação. Isso demonstra que, inicialmente, o constructo pode ser visto como de pouca importância, mas, no conjunto, ele é muito importante, e isso só é verificado por meio da exposição do seu inter-relacionamento com os demais, no todo. Após aplicação e validação do modelo ECSI, procedeu-se ao cálculo das médias para cada constructo.

Esses valores podem ser observados na Tabela 6.

Considerando que a escala do modelo de mensuração vai de 1 até 10 , pode-se concluir, na Tabela 6 , que o serviço prestado está satisfatório na percepção dos usuários, na questão da satisfação geral e na lealdade. Porém, deve-se destacar que o valor percebido do serviço é um item que merece atenção, dado que esse constructo recebeu a média com valor menor.

\section{Análise de diferenças por grupo}

O teste aplicado para verificar possíveis diferenças por grupos em cada um dos constructos é não paramétrico e chama-se Kruskal Wallis. Esse teste não exige normalidade dos dados e é o mais adequado à situação identificada. Quando os construtos são analisados separadamente, por gênero, cidade de origem do usuário, local da residência e motivo de utilização do sistema, verifica-se que não existe diferença significativa nos construtos. Quando analisados por faixa etária e pela possibilidade de que o sistema seja ampliado para demais ruas e quadras da cidade, verifica-se que ocorre diferença significativa em todos os construtos. À medida que a idade dos usuários aumenta, a tendência é de que exista uma avaliação melhor em todos os construtos e, consecutivamente, no serviço prestado. Já quando analisado o fator renda, ocorre diferença significativa somente nos constructos valor e lealdade. Constatou-se que quanto maior a renda do usuário, maior será a aceitação e a utilização do serviço prestado, tornando-se mais leal em relação à utilização do serviço.

\section{Considerações finais}

Verificou-se nesta pesquisa, os fatores determinantes da satisfação e como eles afetam e impactam os diferentes constructos. As variáveis mais importantes da determinação da satisfação foram expectativa e imagem, representando um efeito direto, respectivamente, de 0,353 e 0,313 . 0 constructo que menos impactou na satisfação foi o de qualidade, uma vez que o usuário 
já espera que esse atributo faça parte do serviço prestado e oferecido. Quanto à satisfação geral dos usuários, constata-se que se encontra em um nível positivo, dado que a avaliação média ficou em 7,65 em uma escala que oscila de 1 a 10 . Sugere-se que seja dada mais ênfase aos fatores imagem e expectativa, que afetam positivamente a satisfação dos usuários, e ao constructo valor percebido, que teve menor média $(6,73)$, para que os usuários elevem seu nível de lealdade.

Para os gestores públicos, como sugestão, aborda-se a necessidade de maior atenção às expectativas dos usuários e à imagem do serviço prestado, a fim de melhor retornar o serviço que realmente o usuário espera ter e torná-lo cada vez mais satisfeito. Ainda, recomenda-se uma atenção especial ao construto valor, pois esse fator foi o que recebeu a menor média na avaliação dos usuários. Dessa forma, essa variável apresenta maior potencial de melhora.

A inovação, a modernização e a qualificação contínua do serviço prestado identificam-se como aspectos favoráveis à melhoria, além de novos investimentos em mobilidade urbana, uma vez que o fator visual tem grande valor na percepção dos usuários. $O$ investimento financeiro e contínuo na operacionalização e no funcionamento do sistema tornase fundamental. Sugere-se ainda o desenvolvimento e a concretização do Plano Municipal de Mobilidade Urbana, utilizando-se deste estudo como base para o reconhecimento do perfil do usuário do sistema de estacionamento, fatores diretamente relacionados à sua satisfação enquanto cidadão, assim como a identificação de suas preferências e necessidades.

Em contribuição, um fator que deve constar no documento norteador das ações de políticas públicas (PlanMob) é a valorização, construção de infraestrutura e regulamentação das diferentes formas de deslocamentos por meio de veículos de transporte particular (carro, moto, bicicleta) e de passageiros (ônibus, escolares, táxi etc.), uma vez que a mobilidade implica diretamente no desenvolvimento econômico, social e ambiental da cidade. Torna-se fundamental ainda, além da sincronização positiva entre os diferentes modais, o direcionamento da cidade para maior qualidade de vida.

Por fim, apresenta-se como principal limitação do estudo o fato de que os usuários participantes da pesquisa encontravam-se com pouca disponibilidade de tempo para responder aos questionários devido a seus deslocamentos e compromissos particulares.

\section{Referências}

Amato, S., Vinzi, V. E., \& Tenenhaus, M. (2004). A global Goodness-of-Fit index for PLS structural equation modeling. France: HEC School of Management.

Araújo, J. M. (2013). Estacionamento regulamentado rotativo. Recuperado em 06 de outubro de 2015, de http://www. ctbdigital.com.br/artigos/jaraujo_estacionamento_rotativo.pdf

Assis, A. (2010). Soluções para mobilidade urbana são foco de estudos da pós-graduação. Brasília: Capes. Recuperado em 03 de outubro de 2011, de http://www.capes.gov.br/ servicos/sala-de-imprensa/36-noticias/3872-seminarioaborda-problemas-da-mobilidade-urbana

Bastien, P., Vinzi, V. E., \& Tenenhaus, M. (2015). PLS generalised linear regression. Computational Statistics \& Data Analysis, 48(1), 17-46.

Bennet, R., \& Rundle-Tiele, S. (2004). Customer satisfaction should not be the only goal. Journal of Services Marketing, 18(7), 514-523.

Bloemer, J., \& Odekerken-Schroder, G. (2002). Store satisfaction and store loyalty explained by customer - and store - related factors. Journal of Consumer Satisfaction, Dissatisfaction and Complaining Behavior, 15(14), 68-80.

Brasil. (2002, 10 de janeiro). Código civil: Lei no 10.406, de 10 de janeiro de 2002 (8. ed., p. 27, Série Legislação, No. 202). Brasília: Câmara dos Deputados, Edições Câmara.

Brasil. (2007). PlanMob: construindo a cidade sustentável. Caderno de Referência para elaboração de Plano de Mobilidade Urbana. Brasília: Ministério das Cidades.

Brasil. (2008, 23 de setembro). Código de Trânsito Brasileiro e Legislação complementar em vigor: instituído pela Lei 9.503, de 23 de setembro de 1997. Brasília: DENATRAN.

Brasil. (2012, 03 de janeiro). Lei Federal no 12.587/2012. Institui as diretrizes da Política Nacional de Mobilidade Urbana. Brasília. Recuperado em 20 de julho de 2013, de http://www.planalto.gov.br/ccivil_03/_ato2011-2014/2012/ lei/112587.htm

Ceretta, P. S., \& Righi, M. B. (2012). Mensuração das relações da satisfação dos clientes de telefonia celular com seus antecedentes e consequentes. REGE, 19(4), 607-626.

Chin, W. W. (1998). The partial least squares approach for structural equation modeling. In G. A. Macoulides (Ed.), Modern methods for business research (p. 295-358). Mahwah: Lawrence Erlbaum Associates. 
Chin, W. W., Marcolin, B. L., \& Newsted, P. R. (1996). A partial least squares latent variable modeling approach for measuring interaction effects: results from a monte carlo simulation study and voice mail emotion/adoption study. In Proceedings of the 17th International Conference on Information Systems (p. 21-41). Cleveland: AIS Electronic Library.

Congram, C., \& Friedman, M. (1991). The AMA Handbook of marketing for the services industries. Chicago: American Marketing Association.

Costa, M. S. (2003). Mobilidade Urbana Sustentável: um estudo comparativo e as bases de um sistema de gestão para Brasil e Portugal (Dissertação de mestrado). Escola de Engenharia de São Carlos, Universidade de São Paulo, São Carlos.

Edvardsson, B., Johnson, M.D., Gustafsson, A., \& Strandvik, T. (2000). The effects of satisfaction and loyalty on profits and growth: products versusservices. Total Quality Management \& Business Excellence, 11(7).

Elias, A. C. C. (2001). Estacionamento Rotativo Pago em via pública: Racionalização do uso da via x disposição do usuário em pagar pelo serviço (Dissertação de Mestrado). Mestrado Profissionalizante em Engenharia, Universidade Federal do Rio Grande do Sul, Porto Alegre.

European Customer Satisfaction Index - ECSI. (2013). ECSI PORTUGAL: Índice Nacional de Satisfação do Cliente. Portugal: ECSI. Recuperado em 20 de julho de 2013, de http://www.ecsiportugal.pt/

Fornell, C. (1992). A national customer satisfaction barometer: the Swedish experience. Journal of Marketing, 56(1), 6-21. http://dx.doi.org/10.2307/1252129.

Frente Nacional de Prefeitos - FNP. (2012). A nova mobilidade urbana para a sua cidade: transporte público de qualidade. Brasília: FNP. Recuperado em 10 de fevereiro de 2013, de http://www.ntu.org.br/novosite/mostraPagina. asp? codServico $=19 \& \operatorname{cod}$ Pagina $=852$

Gianesi, I. G. N., \& Corrêa, H. L. (1994). Administração estratégica de serviços. São Paulo: Atlas.

Hair, J. F., Black, W. C., Babin, B. J., Anderson, R. E., \& Tatham, R. L. (2009). Análise multivariada de dados (6. ed). Porto Alegre: Bookman.

Kotler, P. (2000). Administração de marketing: a edição do novo milênio. São Paulo: Prentice Hall.
Kristensen, K., Martensen, A., \& Gronholdt, L. (2000). Customer satisfaction measurement at post denmark: results of application of the european customer satisfaction index methodology. Total Quality Management, 11(7), 10071015. http://dx.doi.org/10.1080/09544120050135533.

Leite, R. S., Gonçalves, C. G., Fo. (2007). Um estudo empírico da aplicação do índice europeu de satisfação de clientes (ECSI) no Brasil. RAM - Revista de Administração Mackenzie, 8(4): 178-200.

Lopes, H. E. G., Pereira, C. C. P., \& Vieira, A. F. S. (2009). Comparação entre os modelos norte americano (ACSI) e europeu (ECSI) de satisfação do cliente: um estudo no setor de serviços. Revista Administração Mackenzie, $10(1), 161-186$.

Marchetti, R., \& Prado, P. H. M. (2004). Avaliação da satisfação do consumidor utilizando o método de equações estruturais: um modelo aplicado ao setor elétrico brasileiro. Revista de Administração Contemporânea, 8(4), 9-32. http://dx.doi. org/10.1590/S1415-65552004000400002.

Olsen, S. (2002). Comparative evaluation and the relationship between quality, satisfaction, and repurchase loyalty. Journal of the Academy of Marketing Science, 30(3), 240-249. http:// dx.doi.org/10.1177/0092070302303005.

Pereira da Silva, D. (2005). Avaliação da qualidade em serviço de entrega em domicílio no setor farmacêutico: uma aplicação do método Servqual, usando a análise fatorial (Dissertação de Mestrado). Programa de Pós-graduação em Métodos Numéricos em Engenharia, Ciências Exatas e de Tecnologia, Universidade Federal do Paraná, Curitiba. Recuperado em 05 de outubro de 2015, de http://www. ppgmne.ufpr.br/arquivos/diss/142.pdf

Pontes, T. F. (2010). Avaliação da Mobilidade Urbana na área metropolitana de Brasília. Brasília: Universidade de Brasília. Recuperado em 23 de março de 2013, de http://bdtd.bce. unb.br/tedesimplificado/tde_arquivos/18/TDE-2011-0208T095657Z-5619/Publico/2010_TaisFurtadoPontes.pdf

Rossi, C. A. V., \& Slongo, L. A. (1998). Pesquisa de satisfação de clientes: o estado-da-arte e proposição de um método brasileiro. Revista de Administração Contemporânea, 2(1), 101125. http://dx.doi.org/10.1590/S1415-65551998000100007.

Silva, D. P. (2005). Avaliação da qualidade em serviço de entrega em domicílio no setor farmacêutico: uma aplicação do método Servqual, usando a análise fatorial (Dissertação de mestrado). Programa de Pós-graduação em Métodos 
Numéricos em Engenharia, Ciências Exatas e de Tecnologia, Universidade Federal do Paraná, Curitiba.

Silveira, J. A. R. S. (2004). Percursos e processo de evolução urbana: o caso da Avenida Epitácio Pessoa na cidade de João Pessoa - PB (Tese de Doutorado). Programa de Pósgraduação em Desenvolvimento Urbano, Universidade Federal de Pernambuco, Recife.

Tenenhaus, M., Esposito, V. V., Chatelin, Y. M., \& Lauro, C. (2005). PLS-path modelling. Computational Statistics \& Data Analysis, 48(1), 159-205. http://dx.doi.org/10.1016/j. csda.2004.03.005.
Toni, D., Schuler, M. (2007). Gestão da imagem: desenvolvendo instrumento para configuração da imagem de produto. Revista de Administração Contemporânea, 11(4), 131-151.

Urdan, A. T., \& Rodrigues, A. R. (1999). O Modelo do índice de satisfação dos clientes norte americanos: um exame inicial no Brasil com equações estruturais. Revista de Administração Contemporânea, 3(3): 109-130. http:// dx.doi.org/10.1590/ S1415-65551999000300006

Vasconcellos, E. A. (2005). A cidade, o transporte e o trânsito. São Paulo: Pró-livros.

Recebido: Jul. 06, 2015

Aprovado: Jan. 16, 2016 